\title{
Implementasi Algoritma Data Encryption Standard Pada Penyandian Record Database
}

\author{
Neti Rusri Yanti ${ }^{1}$, Alimah' ${ }^{2}$, Desi Afrida Ritonga ${ }^{3}$ \\ 1,2,3Mahasiswa Prorgram Studi Teknik Informatika STMIK Budidarma Medan \\ 1,2,3 Jln. Sisingamangaraja No. $338 \mathrm{Sp}$. Limun Medan \\ 1netiry95@gmail.com, ${ }^{2}$ etekalimah@gmail.com, ${ }^{3}$ desiafrida46@gmail.com
}

\begin{abstract}
Record databases are generally still often displayed in text form as information for users, so it can facilitate cryptanalyst to access and provide opportunities to do the leak, distribute or modify the database records. One of the cryptographic algorithms used to secure data is using the DES algorithm to encrypt the data to be stored or sent. The DES algorithm belongs to a cryptographic system of symmetry and is a type of block cipher. DES operates on a 64-bit block size. DES describes 64 bits of plaintext to 64 bits of ciphertext using 56 bits of internal key (internal key) or up-key (subkey). The internal key is generated from an external key 64bit length. This research describes the process of securing database records by encrypting it based on DES algorithm, resulting in text record databases in the form of passwords that are difficult to understand and understand by others. This is done in an attempt to minimize the misuse of database records.
\end{abstract}

Keywords: Cryptography, DES, Database, Record

\begin{abstract}
Abstrak
Record database umumnya masih sering ditampilkan dalam bentuk teks sebagai informasi bagi pengguna, sehingga dapat mempermudah kriptanalis untuk mengakses serta memberi peluang untuk melakukan pembocoran, mendistribusikan maupun memodifikasi record database tersebut. Salah satu algoritma kriptografi yang digunakan untuk mengamankan data yaitu menggunakan algoritma DES untuk mengenkripsi data yang akan disimpan maupun dikirim. Algoritma DES termasuk ke dalam sistem kriptografi simetri dan tergolong jenis cipher blok. DES beroperasi pada ukuran blok 64 bit. DES mengenkripsikan 64 bit plainteks menjadi 64 bit cipherteks dengan menggunakan 56 bit kunci internal (internal key) atau up-kunci (subkey). Kunci internal dibangkitkan dari kunci eksternal (external key) yang panjangnya 64 bit. Penelitian ini menguraikan proses pengamanan record database dengan menyandikannya berdasarkan algoritma DES, sehingga dihasilkan teks record databases dalam bentuk sandi yang sulit dipahami dan dimengerti oleh orang lain. Hal ini dilakukan sebagai upaya untuk meminimalisir tindakantindakan penyalahgunaan record database.
\end{abstract}

Kata Kunci: Kriptografi, DES, Database, Record

\section{PENDAHULUAN}

Masalah keamanan dan kerahasiaan suatu sangatlah yang penting dalam suatu instansi atau pun perusahaan. Data yang akan digunakan ataupun disimpan agar benar-benar aman secara fisik maupun sistem perlu terlebih dahulu untuk diamankan agar tidak dapat dibaca atau dilacak oleh pihak-pihak yang tidak bertanggung jawab [1]. 
Database secara umum merupakan susunan atau kumpulan dari record data yang disimpan dalam komputer yang saling berhubungan dan dapat dijadikan sebagai salah satu sumber dari sistem informasi yang sedang berjalan sehingga mampu memenuhi informasi yang optimal yang dibutuhkan oleh pengguna. Record database masih sering ditampilkan dalam bentuk teks sebagai informasi bagi pengguna, sehingga dapat mempermudah kriptanalis untuk mengakses serta memberi peluang untuk melakukan pembocoran, mendistribusikan maupun memodifikasi record database tersebut [2].

Kriptografi dapat memelihara dan mejaga suatu data agar tetap terpelihara kerahasiaan dan keasliannya melalui tiga aspek yaitu kerahasiaan pesan, keabsahan, keaslian dan ketiadaan penyangkalan. Kemampuan metode kriptografi dalam mengacak isi data, seperti teks, gambar, audio, video dan sebagainya untuk membuat data tidak terbaca, tersembunyi atau berarti semua jalan melalui transmisi atau penyimpanan [3].

Algoritma Data Encryption Standard (DES) merupakan algoritma enkripsi yang paling banyak digunakan di dunia yang diadopsi oleh NIST (National Institue of Standards and Technology) sebagai standar pengolah informasi Federal AS. Plain dienkrip dalam blok-blok 64 bit menjadi 64 bit data ciphertext menggunakan kunci 56 bit kunci internal (internal key). DES mentransformasikan input 64 bit dalam beberapa tahap enkripsi ke dalam output 64 bit. Dengan demikian, DES termasuk block cipher. Berdasarkan tahapan dan kunci yang sama, DES digunakan untuk membalik enkripsi. Kunci internal pada algoritma DES dibangkitkan dari kunci eksternal (external key) 64 bit4]. DES beroperasi pada ukuran blok 64 bit dan termasuk ke dalam sistem kriptografi simetri dan tergolong jenis cipher block. DES mengenkripsikan 64 bit plainteks menjadi 64 bit cipherteks dengan menggunakan 56 bit kunci internal (internal key) atau up-kunci (subkey). Kunci internal dibangkitkan dari kunci eksternal (external key) yang panjangnya 64 bit [5].

Penelitian ini menjabarkan prosedur pengamanan record database berdasarkan algoritma DES, dimana record database yang diamankan akan dienkripsi dengan 56 bit kunci dan melalui 16 round proses untuk menghasilkan cipher yang kuat sehingga dapat mempersulit pihak-pihak yang tidak berhak untuk memecahkan cipher data tersebut kebentuk aslinya.

\section{METODOLOGI PENELITIAN}

\subsection{Database}

Secara umum database merupakan susunan atau kumpulan dari record data yang disimpan dalam komputer. Keterhubungan antara elemen-eleen dalam database dapat dimanfaatkan sebagai salah satu sumber informasi bagi pengguna. Hingga saat ini, masih banyak record database yang masih ditampilkan dalam bentuk teks sebagai informasi bagi pengguna. Hal inilah yang menjadi salah satu celah baggi para kriptanalis untuk dapat mengakses, memanipulasi maupun melakukan pembocoran dan mendistribusikan record database tersebut [2]. 


\subsection{Kriptografi}

Defenisi sederhana dari kriptografi adalah teknik untuk menjaga kerahasian pesan dengan cara menyandikannya sehingga tidak dapat dimengerti lagi maknanya [6]. Kriptografi memiliki algoritma dalam melakukan proses penyandian suatu agar dapat terjaga keasliannya. Algoritma kriptografi terdiri dari tiga fungsi dasar [7]:

a. Enkripsi

Enkripsi merupakan istilah lain dari proses menyandikan data penting ke dalam bentuk simbol-simbol yang tidak dapat dimengerti lagi oleh pihak lain sehinggan keaslian dan keamanan data dapat terjaga.

b. Dekripsi

Dekripsi adalah proses untuk merubah atau mengembalikan data tersandi kebentuk aslinya agar arti data dapat dimengerti oleh penerima.

c. Kunci

Kunci merupakan elemen yang paling penting dalam mengimplementasikan proses enkripsi dan dekripsi. Keamanan kunci di dalam kriptografi menjadi prioritas karena serumit apapun algoritma yang digunakan akan dapat dipecahkan bila kunci yang digunakan berhasil ditemukan. Kunci terbagi menjadi dua bagian, kunci rahasia (private key) dan kunci umum (public key).

Ada beberapa aspek keamanan yang harus dicapai pada penerapan teknik kriptografi, yaitu kerahasiaan (confidentiality), integritas data (data integrity), autentikasi (authentication), ketiadaan penyangkalan (non-repudiation) [8][11]. Beberapa kekuatan yang dimiliki oleh algoritma kriptografi dalam proses mengenkripsi data2][3], yaitu:

a. Konfusi/pembingungan (confusion), yaitu suatu proses dimana teks sulit dikembalikan pada bentuk awal secara tanpa melalui proses dekripsi.

b. Difusi/peleburan (difusion), yaitu suatu proses dimana karakteristik suatu teks dihilangkan sehingga mengamankan suatu informasi.

Umumnya algoritma kriptografi modern beroperasi dalam mode bit. semua data dan informasi (baik kunci, plainteks, maupun cipher teks) dalam operasi mode bit dinyatakan dalam rangkaian (string) bit biner, 0 dan 1. Algoritma enkripsi dan dekripsi memproses semua data dan informasi dalam bentuk rangkaian bit. Rangkaian bit yang menyatakan plainteks dienkripsi menjadi cipher teks dalam bentuk rangkaian bit, demikian sebaliknya.

\subsection{Algoritma Data Encryption Standard}

Algoritma Data Encryption Standard (DES) termasuk ke dalam sistem kriptografi simetri dan tergolong jenis cipher blok. DES beroperasi pada ukuran blok 64 bit dan mengenkripsikan 64 bit plainteks menjadi 64 bit cipher teks dengan menggunakan 56 bit kunci internal (internal key) atau up-kunci (subkey). Kunci internal dibangkitkan dari kunci eksternal (external key) yang panjangnya 64 bit. Adapun proses dari algoritma DES [5] adalah :

a. Blok plainteks dipermutasi dengan matriks permutasi awal (initial permutation atau IP). 
b. Hasil permutasi awal kemudian dienciphering sebanyak 16 kali (16 round). Setiap putaran menggunakan kunci internal yang berbeda.

c. Hasil enciphering kemudian dipermutasi dengan matriks permutasi balikan (invers initial permutation atau IP-1) menjadi blok cipher teks.

Adapun konsep kerja dari algoritma Data Encryption Standard (DES) [5] adalah sebagai berikut:

a. Blok plainteks proses enkripsi dibagi menjadi dua bagian yaitu L[0] dan R[0] yang panjangnya 32 bit. Kemudian masukkan ke dalam putaran 16 round.

b. Setiap putaran i, blok R merupakan masukan untuk fungsi transformasi yang disebut $\mathrm{f}$.

c. Fungsi f dalam blok R dikombinasikan dengan kunci internal Ki. Keluaran dari fungsi $f$ di XOR-kan dengan blok $L$ untuk mendapatkan blok $R$ yang baru.

d. Bagian blok L yang baru langsung diambil dari blok R sebelumnya. Ini adalah satu putaran DES.

Adapun proses kerja pada algoritma DES terdiri dari dua proses, yaitu:

a. Enkripsi

Proses enkripsi (enciphering) terhadap blok plainteks dilakukan setelah permutasi awal (Setiap blok plainteks mengalami 16 kali putaran enciphering. Setiap putaran enciphering merupakan jaringan Feistel yang secara matematis dinyatakan sebagai:

$\mathrm{Li}=\mathrm{Ri}-1$

$\mathrm{Ri}=\mathrm{Li}-1 \oplus \mathrm{f}(\mathrm{Ri}-1, \mathrm{Ki})$

E adalah fungsi ekspansi yang memerluas blok Ri- 1 yang panjangnya 32bit menjadi blok 48 bit. Hasil ekpansi E(Ri-1) diXOR-kan dengan Ki dan menghasilkan vektor $\mathrm{A}$.

$\mathrm{E}(\mathrm{Ri}-1) \oplus \mathrm{Ki}=\mathrm{A}$

Vektor A dikelompokkan menjadi 8 kelompok, setiap kelompok terdiri 6 bit yang menjadi masukan bagi proses substitusi. Proses substitusi dilakukan menggunakan delapan buah kotak-S-Box yaitu S1 sampai S8. Setiap kotak-S-Box menerima masukan 6 bit dan menghasilkan keluaran 4 bit. Kelompok 6-bit pertama disubsitusikan ke dalam kotak S-Box1, kelompok 6-bit kedua disubsitusikan ke dalam kotak S-Box2, dan seterusnya.

b. Dekripsi

Proses dekripsi terhadap cipher teks merupakan kebalikan dari proses enkripsi. Kunci pada proses dekripsi yaitu kebalikan dari kunci proses enkripsi, yang mana terdiri dari K[16], K[15] hingga K[1]. Untuk tiap putaran $1,2, \ldots, 16$, keluaran pada setiap putaran deciphering [ HYPERLINK \I "Roh121" 5 ], adalah:

$\mathrm{Li}=\mathrm{Ri}-1$

$\mathrm{Ri}=\mathrm{Li}-1$ Error! $\left.{ }^{\oplus}\right\} \mathrm{f}(\mathrm{Ri}-1, \mathrm{Ki})$ 


\section{HASIL DAN PEMBAHASAN \\ 3.1 Analisa Masalah}

Penyimpanan data menggunakan database telah umum digunakan oleh setiap instansi, namun penyimpanan secara langsung tanpa memberi suatu keamanan akan dapat menyebabkan data dapat dibobol dan dicuri atau dirusak oleh pihak-pihak yang tidak bertanggung jawab. Solusi yang perlu diterapkan agar data tersebut tetap aman dari penyimpanannya, maka digunakan salah satu algoritma kriptografi untuk mengekripsi data tersebut. Teks record di dalam database akan disandikan menjadi simbol-simbol lain yang tidak dapat lagi dapat dipahami oleh pihak lain. Bila record yang telah disandikan tersebut dibutuhkan oleh pengguna, maka terlebih dahulu dilakukan proses pengembalian record tersandi menjadi karakter record asli. Skema proses pengamanan record database ditunjukkan pada diagram di bawah ini.

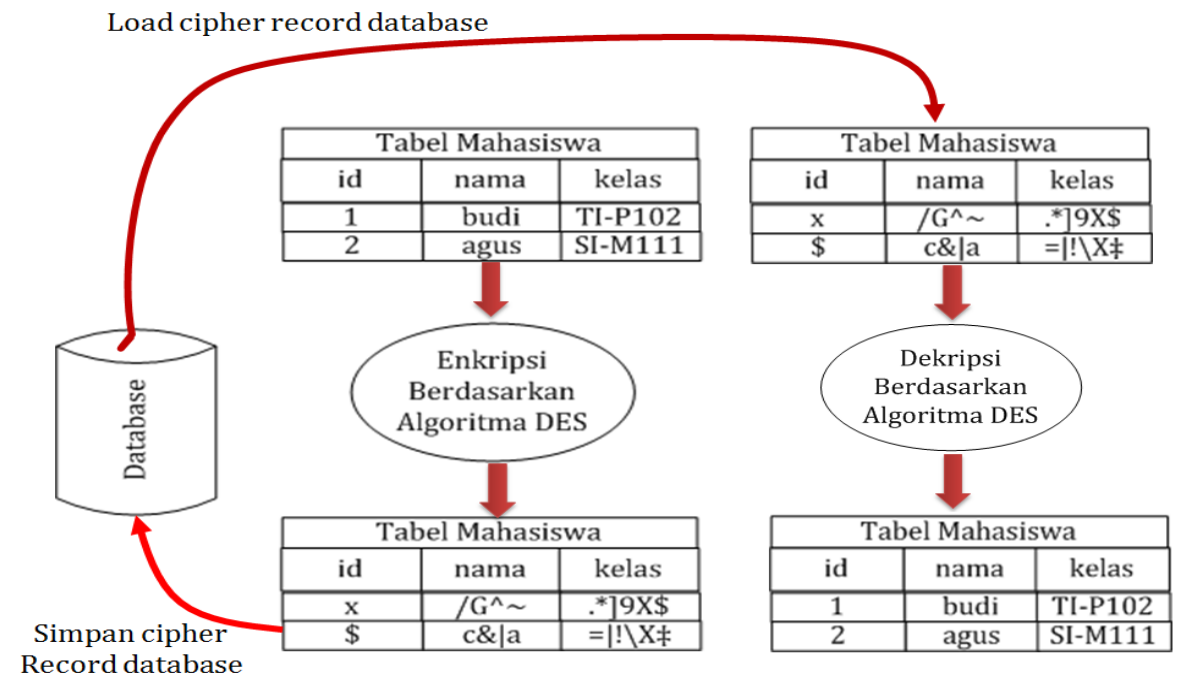

Gambar 1. Skema Penyandian Record Database

Berdasarkan gambar 1 di atas, diketahui bahwa sebelum record tabel disimpan ke dalam database, terlebih dahulu dilakukan proses penyandian teks record tersebut, sehingga teks record yang tersimpan ke dalam tabel database adalah sandi dari teks record asli. Bila makna record tersandi tersebut dibutuhkan, maka terlebih dahulu dilakukan proses dekripsi sehingga record terebut ditampilkan sesuai dengan karakter aslinya.

Langkah-langkah yang dilakukan pada proses enkripsi record mengikuti aturan-aturan yang berlaku pada algoritma DES. Adapun langkah-langkah proses enkripsi record yaitu:

a. Konversikan key ke dalam bentuk biner

b. Lakukan proses pembangkitan kunci sesuai aturan dari algoritma DES.

c. Konversikan karakter dari record yang dipilih ke dalam biner.

d. Gabungkan setiap bit dari plain, setiap bit terdiri dar 32 bit, sehingga dapat ditentukan $\mathrm{R}[0]$ dan $\mathrm{L}[0]$.

e. Lakukan proses round 1-16 sesuai aturan dari algoritma DES. 
Proses enkripsi record database berdasarkan algoritma DES dapat digambarkan seperti pada diagaram di bawah ini.

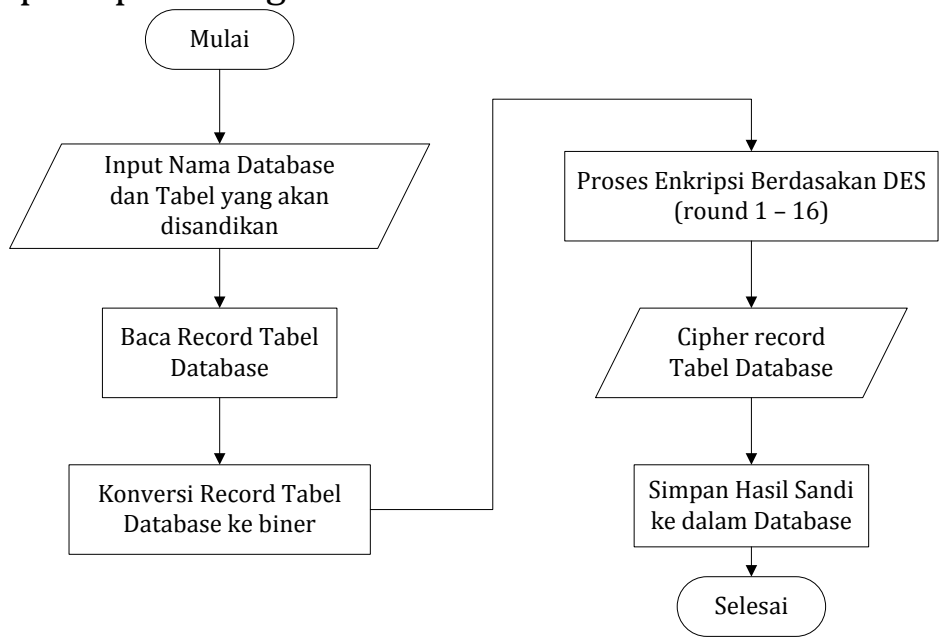

Gambar 2. Diagaram Penerapan DES dalam Penyandian Record Database

\subsection{Implementasi}

Record database yang akan dienkripsi yaitu record dari database mahasiswa dengan nama tblmahasiswa, dimana record dari tabel dapat dilihat di bawah ini.

Table 1. Tabel Mahasiswa

\begin{tabular}{lll}
\hline NPM & Nama & Kelas \\
\hline 14110615 & Neti Rusri Yanti & TI-S1412 \\
14110821 & Alimah & TI-S1401 \\
14110822 & Desi Afrida & TI-M1416 \\
\hline
\end{tabular}

Berdasarkan tabel 1 di atas, sebagai contoh record database yang disandikan adalah :

Plaintext $=$ TI-S1412

Key = NETI\&DKK

a. Proses Generate Key (Pembangkitan Kunci)

Langkah awal adalah mengkonversi kunci ke biner, sehingga dihasilkan biner kunci sebagai berikut:

Tabel 2. Biner Kunci

\begin{tabular}{ccc}
\hline Char Kunci & Decimal & Biner \\
\hline N & 78 & 01001110 \\
E & 69 & 01000101 \\
T & 84 & 01010100 \\
I & 73 & 01001001 \\
$\&$ & 38 & 00100110 \\
D & 68 & 01000100 \\
K & 75 & 01001011 \\
K & 75 & 01001011 \\
\hline
\end{tabular}


Adapun diagaram untuk melakukan proses pembangkitan kunci adalah :

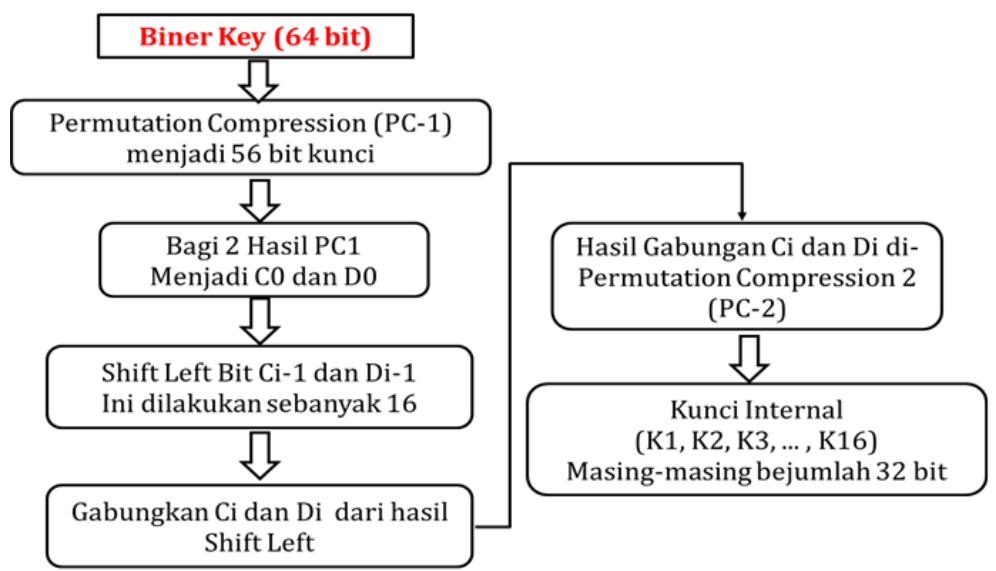

Gambar 3. Diagaram Generate Key

Berdasarkan proses pembangkitan kunci, maka diperoleh kunci untuk proses enkripsi sebagai berikut :

$\mathrm{K}[1]=100000001001011001000010101000001101101101010010$

$\mathrm{K}[2]=101000000000001001010010110011110000100110011000$

$\mathrm{K}[3]=001001000101001000110000100000010101001101011101$

$\mathrm{K}[4]=100001100001000101010000010100111001001010100100$

$\mathrm{K}[5]=000011100100001001010001110100000000110110101101$

$\mathrm{K}[6]=000011110101000100001000000010100011101010011101$

$\mathrm{K}[7]=000010100000000111001001011100110111000110110001$

$\mathrm{K}[8]=000110010100100000001001001000110000100100101011$

$\mathrm{K}[9]=000111010000100010001000001101100100011111010010$

$\mathrm{K}[10]=000100100010000010001100100111011000000101000011$

$\mathrm{K}[11]=000110000000110000000100110001101110011001000000$

$\mathrm{K}[12]=010000000010100000101100011110001010011101001100$

$\mathrm{K}[13]=100000001010010000100100101110001101010010001010$

$\mathrm{K}[14]=110000000000111000100010010011000111011000100011$

$\mathrm{K}[15]=111000001011001000100000101111100110100001101000$

$\mathrm{K}[16]=101000001001000000100110010000110100110000110111$

b. Proses Enkripsi

Kelompokkan biner plain menjadi 64 bit setiap kelompok. Karena karakter yang dienkripsi hanya 8 karakter (64 bit) berarti memenuhi satu kelompok.

Biner Plain = 01010100010010010010110101010011 00110001001101000011000100110010

Lakukan Initial Permutation (IP) terhadap 64 bit plain berdasarkan tabel IP Algoritma DES, maka diperoleh IP dari biner plain adalah :

00001011111110010010010101011110 00000000111101000000011010001000

Bagi 2 kelompok hasil IP biner plain, masing-masing 32 bit. $\mathrm{L}[0]=00001011111110010010010101011110$ 
$\mathrm{R}[0]=00000000111101000000011010001000$

Round 1 (i=1)

1. Expansi Nilai $\mathrm{R}[0]$

$\mathrm{R}[0]=00000000111101000000011010001000$

$\mathrm{E}(\mathrm{R}[0]=000000000001011110101000000000001101010001010000$

2. $\mathrm{E}(\mathrm{R}[0]$ di-XOR dengan $\mathrm{K}[1]$

3. $\mathrm{E}(\mathrm{R}[0]=000000000001011110101000000000001101010001010000$

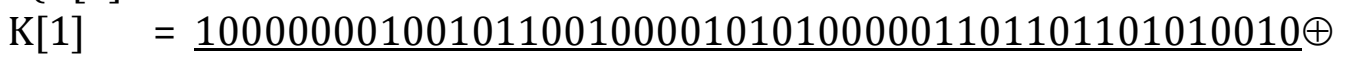

$\mathrm{A}[1]=100000001000000111101010101000000000111100000010$

4. A[1] disubsitusikan ke dalam S-Box DES

Tabel 3. Hasil S-Box

\begin{tabular}{|c|c|c|c|c|c|}
\hline \multirow[b]{2}{*}{$\begin{array}{l}\text { Klpk } \\
\text { A[1] }\end{array}$} & \multirow[b]{2}{*}{$\begin{array}{c}\text { Biner } \\
\text { Hasil klpk }\end{array}$} & \multicolumn{2}{|c|}{ Decimal dari Biner } & \multirow[b]{2}{*}{$\begin{array}{l}\text { Hasil } \\
\text { SBOX } \\
{[\text { Dec] }}\end{array}$} & \multirow[b]{2}{*}{$\begin{array}{l}\text { Biner } \\
\text { Hasil } \\
\text { SBOX }\end{array}$} \\
\hline & & $\begin{array}{l}\text { b1, b6 } \\
\text { [baris] }\end{array}$ & $\begin{array}{l}\mathrm{b} 2, \mathrm{~b} 3, \\
\text { b4,b5 } \\
{[\mathrm{klpk}]}\end{array}$ & & \\
\hline 1 & 100000 & 2 & 0 & 4 & 0100 \\
\hline 2 & 001000 & 0 & 4 & 6 & 0110 \\
\hline 3 & 000111 & 1 & 3 & 9 & 1001 \\
\hline 4 & 101010 & 2 & 5 & 11 & 1011 \\
\hline 5 & 101000 & 2 & 4 & 10 & 1010 \\
\hline 6 & 000000 & 0 & 0 & 12 & 1100 \\
\hline 7 & 111100 & 2 & 14 & 9 & 1001 \\
\hline 8 & 000010 & 0 & 2 & 8 & 1000 \\
\hline
\end{tabular}

Gabungkan kembali biner hasil S-Box, sehingga didapatkan :

$\mathrm{B}[1]=01000110100110111010110010010010$

5. Permutasikan B[1], berdasarkan tabel P-Box DES

$\mathrm{B}[1] \quad=01000110100110111010110010010010$

Permutasikan berdasarkan tabel P-BOX, sehingga didapatkan :

$\mathrm{P}[1]=11010111010000101000000111011001$

6. Mendapatkan Nilai R[1] dan L[1]

$\mathrm{R}[1] \quad=\mathrm{P}[1] \oplus \mathrm{L}[0]$

$\mathrm{P}[1]=11010111010000101000000111011001$

$\mathrm{L}[0] \quad=00001011111110010010010101011110 \oplus$

$\mathrm{R}[1]=\mathbf{1 1 0 1 0 1 0 0 1 0 1 1 1 0 0 1 1 0 1 0 0 1 0 0 1 0 0 0 0 1 1 1}$

$\mathrm{L}[1] \quad=\mathrm{R}[0]$

L[1] = 00000000111101000000011010001000

Seterusnya untuk Round 2-16 dilakukan dengan proses yang sama dengan Round 1, hingga dapatlah hasil cipher akhir seperti berikut ini.

Tabel 4. Hasil Proses Enkripsi (Round 16)

\begin{tabular}{ccc}
\hline Biner & Dec & Char Cipher \\
\hline 11100101 & 229 & å \\
10100000 & 160 & \\
11000110 & 198 & Е \\
11100001 & 225 & á
\end{tabular}




\begin{tabular}{ccc}
\hline Biner & Dec & Char Cipher \\
\hline 11000101 & 197 & $\AA$ \\
00111001 & 57 & 9 \\
00110000 & 48 & 0 \\
00001110 & 14 & \\
\hline
\end{tabular}

Sehingga bila proses enkripsi ini diterapkan pada masing-masing field tabel, maka record tabel akan terlihat seperti berikut.

Table 5. Tabel Mahasiswa yang Telah Dienkripsi

\begin{tabular}{|c|c|c|}
\hline NPM & Nama & Kelas \\
\hline$\hat{\mathrm{E}}^{0}$, \}šy*0 & Š\%oc ${ }^{\wedge *} \pitchfork A \tilde{A} n ̃ ?=8 \& \%$ & å ÆáÁ90 \\
\hline$\left.\hat{\mathrm{E}^{\circ}},\right\} ?<\$ !$ & 1êïbh5 & ‘ $7 \mathrm{TiE}[]$ \\
\hline$\left.\left.\hat{\mathrm{E}}^{\mathrm{o}},\right\} \backslash\right]^{\wedge}$ & 2Ýî'> & “тW'zœ8¥ \\
\hline
\end{tabular}

c. Proses Dekripsi

Proses dekripsi berdasarkan algoritma DES dilakukan seperti proses enkripsi, hanya saja susunan kunci pada proses dekripsi digunakan secara terbalik. Artinya dimulai dari K[16], K[15], K[14], ...., K[1]. Proses dekripsi diawali dengan memanfaatkan biner-biner cipher yang dibaggi menjadi dua kelompok yaitu L[0] dan R[0]. Dua blok ini kemudian di permutasikan berdasarkan tabel permutasi invers (IP1). Output dari dekripsi adalah blok L[0] dan R[0] sehingga didapatkan biner-biner plaintext seperti semula.

\section{KESIMPULAN}

Berdasarkan pembahasan dalam penelitian ini, maka disimpulkan bahwa:

a. Penyandian record database berdasarkan algoritma DES mampu mempersulit pihak-pihak lain untuk memahami dan mengerti isi dari record database.

b. Penyandian record database diawali dengan penentuan nama database dan pemilihan tabel yang memiliki record yang akan disandikan, dimana maasing-masing record pada tabel yang dipilih disandikan berdasarkan algoritma DES.

c. Tingkat keamanan dari yang dibuat cukup aman karena algoritma DES memiliki panjang kunci yang besar. Kunci internal yang berjumlah 56 bit didapatkan dari kunci eksternal yang berjumlah 64 bit.

\section{DAFTAR PUSTAKA}

[1] S.H. Suryawan, Hamdani, "Pengamanan Data File Dengan Menggunakan Algoritma Enkripsi Rivest Code 5 ," Jurnal Informatika Mulawarman, vol. Vol. 8, No. 2 , pp. 44-49, 2013.

[2] E. Setyaningsih, Kriptografi \& Implementasinya Menggunakan Matlab, Yogyakarta:Andi, 2015.

[3] T. Zebua and E. Ndruru, "PENGAMANAN CITRA DIGITAL BERDASARKAN MODIFIKASI ALGORITMA RC4," J. Teknol. Infomasi dan Ilmu Komput., vol. 4, no. 4, pp. 275-282, 2017. 
[4] E. Setyaningsih, "Penyandian Citra Menggunakan Metode Playfair Cipher", J. Teknol., vol. 2, no. 2, pp. 213-219, 2009.

[5] Hamdani, S.H. Suryawan, A. Septiarini,"Pengujian Algoritma Rivest Code 5 Untuk Enkripsi Struktur File Dokumen," Jurnal Informatika Mulawarman, vol. Vol. 8 No. 2, pp. 44-49, Juni 2013.

[6] E. Aribowo, "Aplikasi Pengamanan Dokumen Office Dengan Algoritma Kriptografi Kunci Asimetris Elgamal,” J. Inform., vol. 2, no. 2, pp. 209-219, 2008.

[7] Rifki Sadikin, Kriptografi Untuk Keamanan Jaringan dan Implementasinya dalam Bahasa Java, Yogyakarta: Andi, 2012.

[8] H. Pandiangan and S. Sijabat "PERANCANGAN MEDIA PENGIRIMAN PESAN TEKS DENGAN PENYANDIAN PESAN MENGGUNAKAN ALGORITMA RC4 BERBASIS WEB ," Jurnal Matik Penusa , vol. Volume XIX, No. 1 , no. ISSN 20883943 , pp. 63-71, Juni 2016

[9] T. Zebua, "ANALISA DAN IMPLEMENTASI ALGORITMA TRIANGLE CHAIN PADA PENYANDIAN RECORD DATABASE," Pelita Inform. Budi Darma, vol. 3, no. 2, pp. 37-49, 2013.

[10] N. Widyastuti, "Pengembangan Metode Beaufort Cipher Menggunakan Pembangkit Kunci Chaos," J. Teknol., vol. 7, no. 1, pp. 73-82, 2014.

[11] U. R. S. Lubis, Mesran, and T. Zebua, "Implementasi Algoritma Chua Chaotic Noise Pada Enkripsi Citra RGB," in KOMIK (Konferensi Nasional Teknologi Informasi dan Komputer), 2017, vol. I, no. 1, pp. 220-224. 